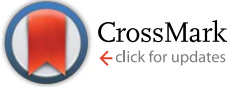

Cite this: Chem. Sci., 2015, 6, 1420

Received 21st October 2014 Accepted 5th December 2014

DOI: $10.1039 / c 4 s c 03224 a$

www.rsc.org/chemicalscience

\section{Solid state organic amine detection in a photochromic porous metal organic framework $\dagger$}

\author{
Arijit Mallick, ${ }^{\text {ab }}$ Bikash Garai, ${ }^{\text {ab }}$ Matthew A. Addicoat, ${ }^{c}$ Petko St. Petkov, ${ }^{c}$ \\ Thomas Heine ${ }^{c}$ and Rahul Banerjee ${ }^{\star a b}$
}

\begin{abstract}
A new $\mathrm{Mg}(\mathrm{II})$ based photochromic porous metal-organic framework (MOF) has been synthesized bearing naphthalenediimide (NDI) chromophoric unit. This MOF (Mg-NDI) shows instant and reversible solvatochromic behavior in presence of solvents with different polarity. $\mathrm{Mg}-\mathrm{NDI}$ also exhibits fast and reversible photochromism via radical formation. Due to the presence of electron deficient NDI moiety, this MOF exhibits selective organic amine (electron rich) sensing in solid state. The organic amine detection has been confirmed by photoluminescence quenching experiment and visual color change.
\end{abstract}

\section{Introduction}

Transformation of the chemical information stored in a molecule into an analyzable signal has drawn researchers' attention for over two decades. ${ }^{1}$ A chemical sensor can detect an analyte through the change in color, luminescence, conductivity, etc. ${ }^{2}$ However, analytes like explosives, hazardous chemicals, or gases, harmful radiations and bioactive reagents need to be detected in very low concentrations in order to avoid the danger inherent in them. In this regard, porous crystalline chemical sensors are quite interesting because of their quick, reversible and recyclable sensing ability. ${ }^{3}$ Metal organic frameworks (MOFs) are one important class of porous crystalline materials constructed by the co-ordination of metal ions with organic linkers. ${ }^{4}$ Such arrangement creates definite pores inside their structure allowing the incoming analyte to interact with the framework or another preloaded material. MOF based sensors generally interact with the incoming analytes in three different ways: (i) analyte-luminescent metal ion interaction, ${ }^{5}$ (ii) analyte-luminescent organic linker interaction, ${ }^{6}$ and (iii) analytetrapped luminescent material interaction. ${ }^{7}$ Among these, the most efficient way to synthesize a MOF based chemical sensor is to utilize the analyte-organic linker interaction, because each analyte produces distinct signal upon interaction with the luminescent MOF linkers.

\footnotetext{
${ }^{a}$ Physical/Materials Chemistry Division, CSIR-National Chemical Laboratory, Dr Homi Bhabha Road, Pune 411008, India. E-mail: r.banerjee@ncl.res.in; Tel: +91 2025902535

${ }^{b}$ Academy of Scientific and Innovative Research (AcSIR), New Delhi, India

${ }^{c}$ School of Engineering and Science, Jacobs University Bremen Campus Ring 1, 28759 Bremen, Germany

$\uparrow$ Electronic supplementary information (ESI) available: Experimental procedures and additional supporting data. CCDC 1024270 and 1024271. For ESI and crystallographic data in CIF or other electronic format see DOI: $10.1039 / \mathrm{c} 4 \mathrm{sc} 03224 \mathrm{a}$
}

Herein, we report a porous solvatochromic MOF, constructed from the environmentally friendly element $\mathrm{Mg}$ (II) and naphthalenediimide (NDI) based fluorescent linker, capable of sensing a diverse range of solvents in less than 60 seconds and having ability to detect the new incoming solvent during fast analyte-solvent exchange. Chemical entities such as organic amines have enormous importance in polymer, dye and pharmaceutical industries. ${ }^{8}$ However, most of these amines are colorless, making their differentiation via visual inspection difficult. These amines are also hazardous to the environment, and hence spillage of these materials should be sensed efficiently in order to prevent any probable harm. Traditional chemical sensors generally dissolve or decompose in presence of such analytes. ${ }^{9}$ Porous MOFs, on the other hand, bear an advantage over these traditional chemical sensors because of their heterogenous nature and ability to be used over multiple cycles. However, solvatochromic MOFs reported in the literature, have sluggish reversibility and require long detection time and/or sophisticated instrumental fabrication. ${ }^{10}$ Hence, it is still quite challenging to make a porous MOF which capable of sensing an analyte quickly and reliably. This $\mathrm{Mg}$-NDI MOF, reported in this paper, is able to sense small sized amines by visual color change as well as photoluminescence quenching, making it a dual sensor of solvents and amines. Apart from these chemical entities, $\mathrm{Mg}-$ NDI is also able to detect the presence of radiations by showing reversible color change. This photochromism adds as another sensing property for $\mathrm{Mg}-\mathrm{NDI}$. To the best of our knowledge, this is the first report of a MOF where both solvatochromism and photochromism could be observed in one system. This type of dual sensing property is possible because of the presence of chromophoric unit forming the porous structure. 


\section{Synthesis}

This solvatochromic MOF (Mg-NDI) was synthesized from the solvothermal reaction of $\mathrm{Mg}\left(\mathrm{NO}_{3}\right)_{2} \cdot 6 \mathrm{H}_{2} \mathrm{O}(24 \mathrm{mg}, 0.093 \mathrm{mmol})$ and $N, N^{\prime}$-bis(5-isophthalic acid)naphthalenediimide $\left(\mathrm{H}_{4} \mathrm{BINDI}\right.$, $21 \mathrm{mg}, 0.035 \mathrm{mmol})$ in a mixture of DMF $(4 \mathrm{~mL})$ and $3 \mathrm{~N} \mathrm{HCl}(0.2$ $\mathrm{mL})$ at $90^{\circ} \mathrm{C}$.

\section{Result and discussion}

Mg-NDI MOF crystallized in $P 2 / c$ space group and the secondary building unit (SBU) contains two different hexacoordinated $\mathrm{Mg}$ (II) metal centers, two BINDI ligands, two coordinated DMF and one water molecule. The first $\mathrm{Mg}$ (II) center is coordinated to the carboxylate oxygen atoms of isophthalate moieties present in BINDI ligand while the second $\mathrm{Mg}$ (II) center is coordinated to three BINDI carboxylate oxygen atoms, two DMF and one water molecules. The PXRD pattern of the as-synthesized material matched well with the simulated pattern, except for the additional small peak at $2 \theta=8.8^{\circ}$, possibly originated from the disordered solvent molecules present in the framework (Fig. S7 in ESI $\dagger$ ). Mg-NDI retained its PXRD patterns after addition of analyte molecules (such as various solvents and amines), indicating the retention of crystallinity after incorporation of guest molecules in the framework. Generation of no additional peak in the PXRD pattern suggests that the solvent molecules are not coordinated to the metal ions, rather they are situated within the pores and weakly interacting with the pore walls to generate the necessary analyte response.

FT-IR analysis of the vacuum dried MOF (Fig. S9 in ESI $\dagger$ ) shows sharp peaks at 1656 and $1550 \mathrm{~cm}^{-1}$ due to the presence of amide and carboxylate carbonyl functionalities, respectively. In comparison to the free ligand, this amide carbonyl stretching frequency $\left(1708 \mathrm{~cm}^{-1}\right)$ got shifted by $52 \mathrm{~cm}^{-1}$, possibly due to the change in dihedral angle from 128 to $103^{\circ}$ in the crystal lattice (Fig. S5 in ESI †). Generation of additional broad peak at 3305 and sharp peaks at 2971 and $1044 \mathrm{~cm}^{-1}$ account for the O$\mathrm{H}, \mathrm{C}-\mathrm{H}$ and $\mathrm{C}-\mathrm{O}$ stretching frequencies for the $\mathrm{EtOH}$ present in EtOH@Mg-NDI. Such characteristic peaks (Fig. S9 in ESI $\dagger$ ) were also observed for DMF, DEF, DMA incorporated MOFs (1649, 1642, $1607 \mathrm{~cm}^{-1}$, respectively for carbonyl stretching), DMSO@Mg-NDI $\left(1015 \mathrm{~cm}^{-1}\right.$ for $\mathrm{S}=\mathrm{O}$ stretching $)$ and MeCN@Mg-NDI (2253 $\mathrm{cm}^{-1}$ for C-N stretching). These weakly interacting solvent molecules do not affect the thermal stability of the MOF and are released from the framework between 80$150{ }^{\circ} \mathrm{C}$ during TGA which causes $\sim 15 \%$ weight loss of the material (Fig. S11 in ESI $\uparrow$ ). Mg-NDI framework is stable up to $300{ }^{\circ} \mathrm{C}$ under $\mathrm{N}_{2}$ atmosphere.

In the crystal structure of free $\mathrm{H}_{4}$ BINDI ligand, the chromophoric naphthalenediimide (NDI) moieties are $\pi$-stacked and separated by a distance of $3.3 \AA$ (Fig. S6 in ESI†े). However, within the MOF lattice, the moieties are separated by a longer distance of $7.1 \AA$ (Fig. 1), preventing them from forming any $\pi$ stacked assembly. This spacing allows the NDI moieties to behave as discrete fragments, unlike $\mathrm{H}_{4} \mathrm{BINDI}$ ligand where the smaller spacing and existing $\pi$-interaction prohibit the analyte molecules from interacting with the chromophore. Analyte molecules can pass through the pores of Mg-NDI MOF, creating a definite interaction with the pore walls constructed by the BINDI linkers (Section S10 in ESI $\dagger$ ). $\mathrm{N}_{2}$ adsorption analysis also indicated the presence of $224 \mathrm{~m}^{2} \mathrm{~g}^{-1}$ available surface area within this MOF (Fig. 3c). When the dark-brown colored assynthesized MOF was placed in ethanol, the color of the resulting compound (EtOH@Mg-NDI) changed to bright-

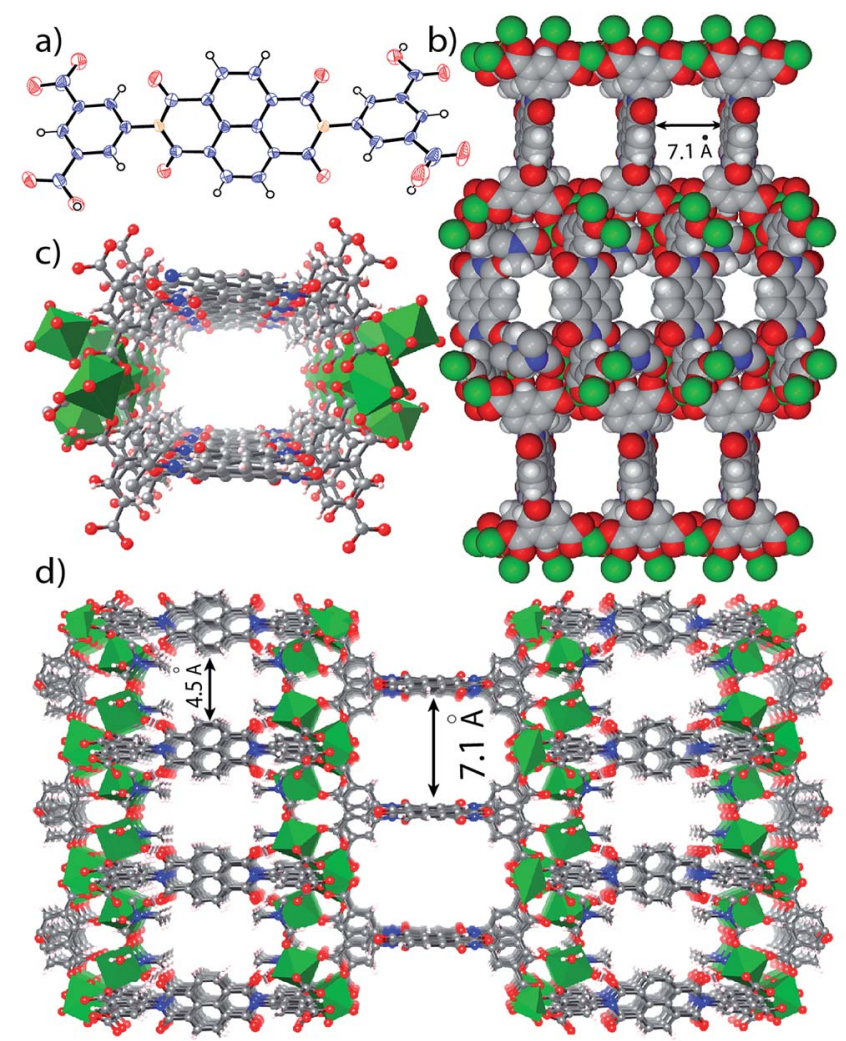

Fig. 1 (a) ORTEP diagram of $\mathrm{H}_{4} \mathrm{BINDI}$; (b) space filled diagram of $\mathrm{Mg}-$ $\mathrm{NDI}$; (c) perspective view of a single pore and (d) perspective view of the extended structure of $\mathrm{Mg}-\mathrm{NDI}$.

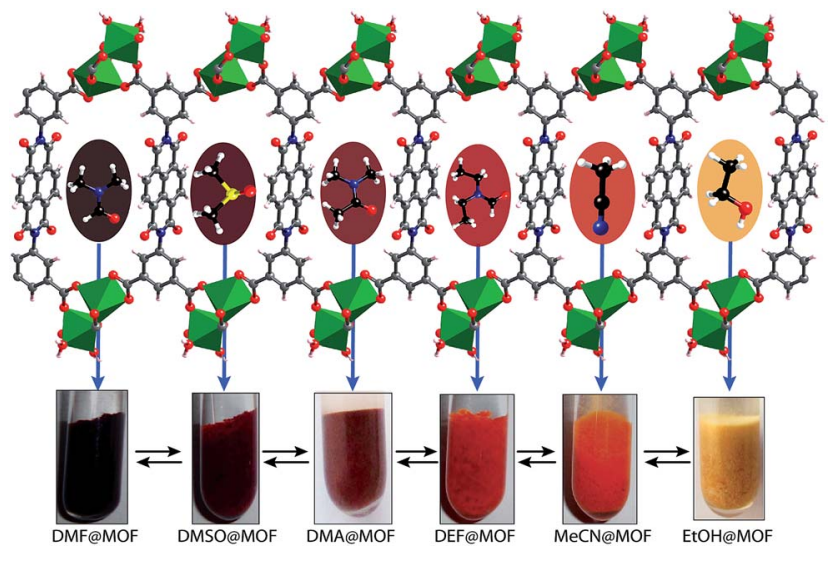

Fig. 2 Schematic representation of $\mathrm{Mg}-\mathrm{NDI}$ crystals showing different colors in different solvents. Hypsochromic shift was found to be observed with the increase in polarity of the solvent medium. 

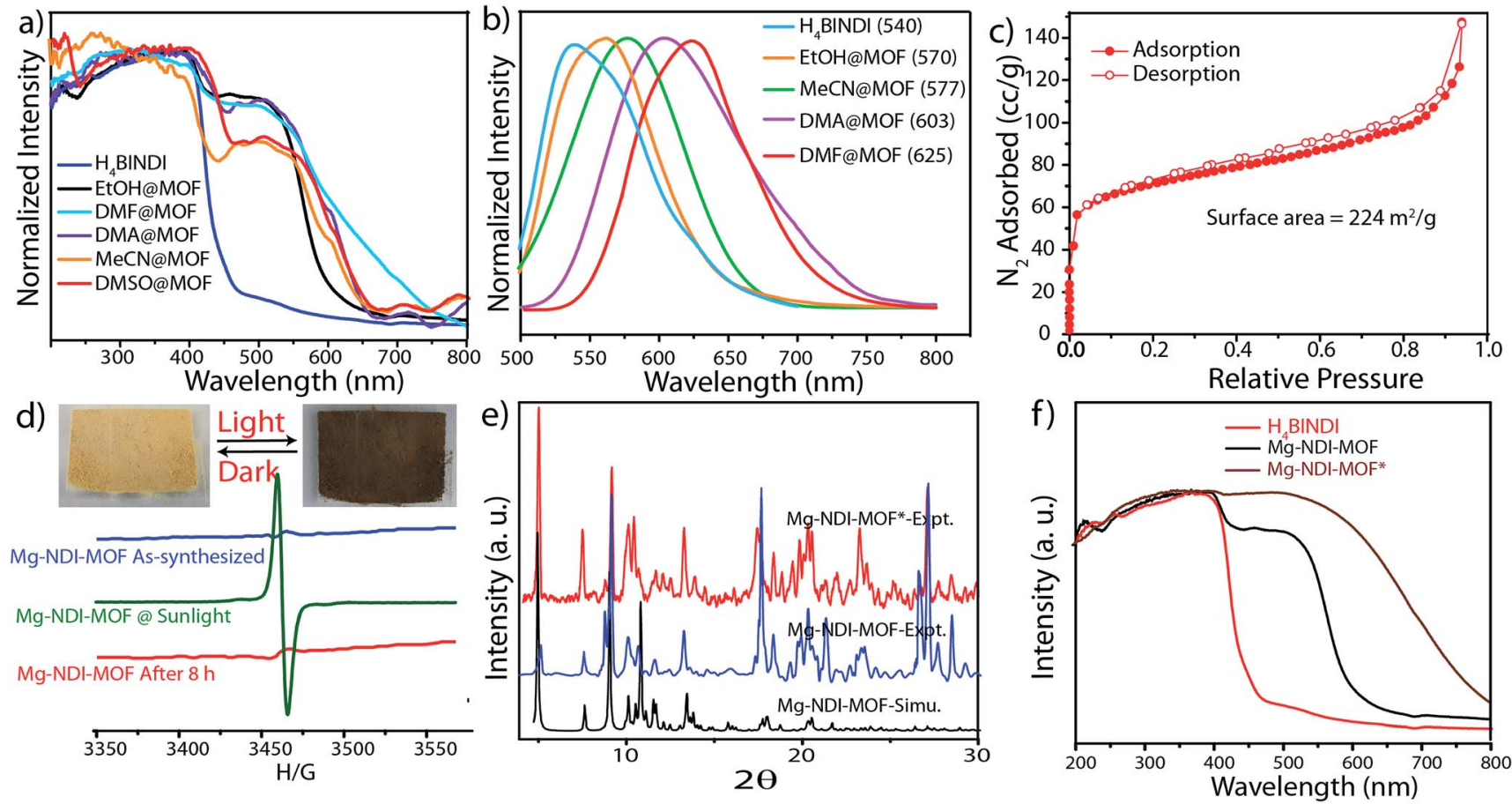

Fig. 3 (a) Solid state UV-vis spectra, (b) solid state photoluminescence of $\mathrm{Mg}-\mathrm{NDI}$ crystals soaked in different solvents; (c) $\mathrm{N}_{2}$ adsorption isotherm for Mg-NDI; (d) ESR spectra of Mg-NDI crystals before and after irradiation of sunlight; (inset) photograph representing the reversible photochromic behavior of Mg-NDI MOF crystal in sunlight and dark; (e) PXRD patterns of Mg-NDI crystals before and after irradiation of sunlight; (f) solid state UV-vis spectra of $\mathrm{H}_{4} \mathrm{BINDI}$ (red), Mg-NDI (black) and Mg-NDI* (brown).

yellow. Similar solvent exchange with other solvents like DMSO, DEF, DMA, MeCN, generates different colors [brown, dark red, red, orange, respectively; Fig. 2] for the MOF depending on the polarity of the solvent. This color change is instant and reversible, i.e. after placing the MOF into the solvent; it converted into the corresponding distinct colored MOF in less than 60 seconds. This fact indicated that the interaction of the incorporated solvent and framework is short ranged and weak, allowing the external bulk solvents to easily replace the core solvent already present inside the porous framework.

Solid state UV-vis spectra revealed that the solvent incorporated $\mathrm{Mg}$-NDI samples showed absorption in the visible range and absorption maxima are consistent with the solvent polarity. The UV-vis spectrum of both $\mathrm{Mg}-\mathrm{NDI}$ and free $\mathrm{H}_{4} \mathrm{BINDI}$ ligand showed a strong absorption band at $370 \mathrm{~nm}$ (Fig. 3a), which corresponds to the $\mathrm{n}-\pi^{*}$ and $\pi-\pi^{*}$ transition of the aromatic carboxylate ligands. ${ }^{11}$ In addition, a shoulder peak around 515 $\mathrm{nm}$ can also be observed in Mg-NDI, which could be attributed to an intermolecular electron-transfer transition. The UV-vis spectra of solvent@Mg-NDI (Fig. 3a) displayed a gradual broadening of absorption band in the region 515-680 $\mathrm{nm}$ with respect to different solvent polarity, which may arise from the intermolecular electron-transfer transition from solvent to BINDI linker within the MOF framework. The band gap energies of these solvent incorporated MOFs were calculated from UV-vis data which show that band gap energy of DMF@Mg-NDI and EtOH@Mg-NDI are $1.63 \mathrm{eV}$ and $2.06 \mathrm{eV}$, respectively and are extreme values for all the tested solvents. The band gap energies of other solvent incorporated MOFs were found to increase with the increment of the solvent polarity $(1.87,1.88,1.91$, and 1.92 eV for DMA, DMSO, DEF, and MeCN, respectively; Fig. S12b in ESI $\dagger$ ). Mg-NDI also exhibited solvent-dependent photoluminescence (PL). The PL spectrum of EtOH@Mg-NDI shows an emission at $570 \mathrm{~nm}$ and DMF@Mg-NDI shows an emission at $625 \mathrm{~nm}$ upon excitation at $515 \mathrm{~nm}$, i.e. a $55 \mathrm{~nm}$ shift of $\lambda_{\mathrm{em}}$ was observed upon changing the solvent from EtOH to DMF. With increasing solvent polarity $[\mathrm{DMF}<\mathrm{DMSO}<\mathrm{DEF}<\mathrm{MeCN}<$ $\mathrm{EtOH}$ ] a gradual blue shift of $\lambda_{\mathrm{em}}$ was observed which correlates with the band gap energies of the solvent@Mg-NDI MOFs, showing that Mg-NDI MOF has a negative solvatochromic effect. The solid $\mathrm{H}_{4}$ BINDI ligand showed the photoluminescence emission maxima at $540 \mathrm{~nm}$ upon excitation at $370 \mathrm{~nm}$ (Fig. 3b). Whereas, the PL spectra of the dry Mg-NDI MOF showed strong emission bands centered at $\lambda_{\mathrm{em}}=570 \mathrm{~nm}$ upon excitation at $515 \mathrm{~nm}$. The probable reason behind the strong red shift of emission maxima is the coupling interaction between the neighboring ligands through $\mathrm{Mg}$ (II) inside the framework. Thus, the solvatochromism of Mg-NDI MOF is much better than that of the $\mathrm{H}_{4} \mathrm{BINDI}$ ligand itself.

It is noteworthy that Mg-NDI also shows sensitivity towards sunlight irradiation. The yellow colored crystals of Mg-NDI undergo photochromic transition and become black within five minutes. The black crystals then regain their yellow color when kept in dark for 8 hours at ambient condition. PXRD data of $\mathrm{Mg}$-NDI collected before and after the photochromic transition are exactly identical (Fig. 3e) which proves that no structural change is caused because of the irradiation. However, the UV-vis spectra show an abrupt change in absorption band (Fig. 3f) 
which reveals that reversible photochromism may be resulted from an electron-transfer chemical process inside the structure, and not from a structural transformation. The UV-vis spectrum of the irradiated $\mathrm{Mg}-\mathrm{NDI}\left(\mathrm{Mg}-\mathrm{NDI}^{*}\right)$ displays a transformation of the tiny shoulder peak at $515 \mathrm{~nm}$ for Mg-NDI, into a broad band in the region 515-700 nm (Fig. 3f). This broadening is arising from the photo-induced electron-transfer transition in Mg-NDI*. NDI moiety is known to be redox-active and can generate radicals upon light irradiation. ${ }^{11}$ Therefore, besides $\pi$ $\pi$ electron-transfer, this photochromic process may also arise from the photo-induced radical generation of organic ligand. This radical generation has been confirmed by ESR spectra. $\mathrm{Mg}-$ NDI exhibits no ESR signal, but Mg-NDI* shows a single-peak radical signal with a $g$ value of 1.9514 (Fig. 3d).

As the Mg-NDI framework is electron deficient in nature due to the presence of NDI chromophore, we decided to check its ability to sense electron rich chemical species. Among several electron rich chemical species, this MOF can selectively sense small sized organic amines by visual color change as well as quenching of its fluorescence efficiency. Electron rich organic amines can form charge transfer complex with the NDI moieties within the framework, resulting a change in color as well as photoluminescence property. Treatment of $\mathrm{Mg}-\mathrm{NDI}$ with various organic amines like aniline, hydrazine, ethylene diamine, triethylamine, dimethylamine, 1,3-propanediamine, ethylamine, methylamine showed a distinct color change (to black) over other functionalized analytes like chlorobenzene, toluene, benzene, phenol, 4-nitrophenol, nitrobenzene, 4-bromotoluene, etc. (Fig. 4a). This color change is extremely rapid and very prominent and can be easily detected from naked eye inspection. $\mathrm{Mg}-\mathrm{NDI}$ is able to detect the presence of amine from a very low concentration $\left(10^{-5} \mathrm{M}\right)$ in the solid state.

Chemical sensing using as-synthesized solid MOF samples is rarely reported in the literature. In all the previous reports, analyte sensing has been done with a suspension of the sensor MOF, or by making a thin film probably due to their poor efficiency. ${ }^{12}$ Presence of the chromophoric NDI moiety has made Mg-NDI capable to sense organic amines in solid state. To explore the ability of $\mathrm{Mg}$-NDI to sense a trace quantity of amine, fluorescence-quenching experiment were performed with addition of analytes, with increasing concentration to the fixed amount Mg-NDI. Rapid and strong fluorescence quenching was observed upon increasing the concentration of amine solution. The MOF was tested for its sensing ability against a wide range of amines like aniline, ethylenediamine, triethylamine, hydrazine, etc. where an instant color change of the solid material was observed for the case of hydrazine, methylamine, ethylamine, dimethylamine and ethylenediamine. In the cases of aniline and triethylamine, the rate of color change was found to be relatively slow because of their bulky size. The PL spectra revealed that the tested amines showed prominent PL quenching response over other analytes which can also be detected by visual color change to black. The fluorescence quenching can be attributed to the donor-acceptor electron transfer between amines and MOF. To understand the electron transfer process, the HOMO and LUMO energy of Mg-NDI was determined by cyclic voltammetry measurement (Fig. S23 in ESI $\dagger$ ). The electron transfer happens because the HOMO energy $(-6.02 \mathrm{eV})$ of $\mathrm{Mg}-\mathrm{NDI}$ is lower than that of amine analytes [hydrazine: $-5.47 \mathrm{eV}$, ethylenediamine: $-5.60 \mathrm{eV}$, aniline: $-5.63 \mathrm{eV}$ and triethylamine: $-5.76 \mathrm{eV}$ ]. The electron transfer from hydrazine to $\mathrm{Mg}-\mathrm{NDI}$ is faster than other amines because of higher energy difference as compare to other amines (Fig. 5a). In case of phenol the PL quenching is also observed due to the presence of electron rich phenolic hydroxy groups, but no color change has been observed in visible light. Few experiments have been designed to check vapor phase sensing ability of Mg-NDI. In a typical experiment, the vacuum dried

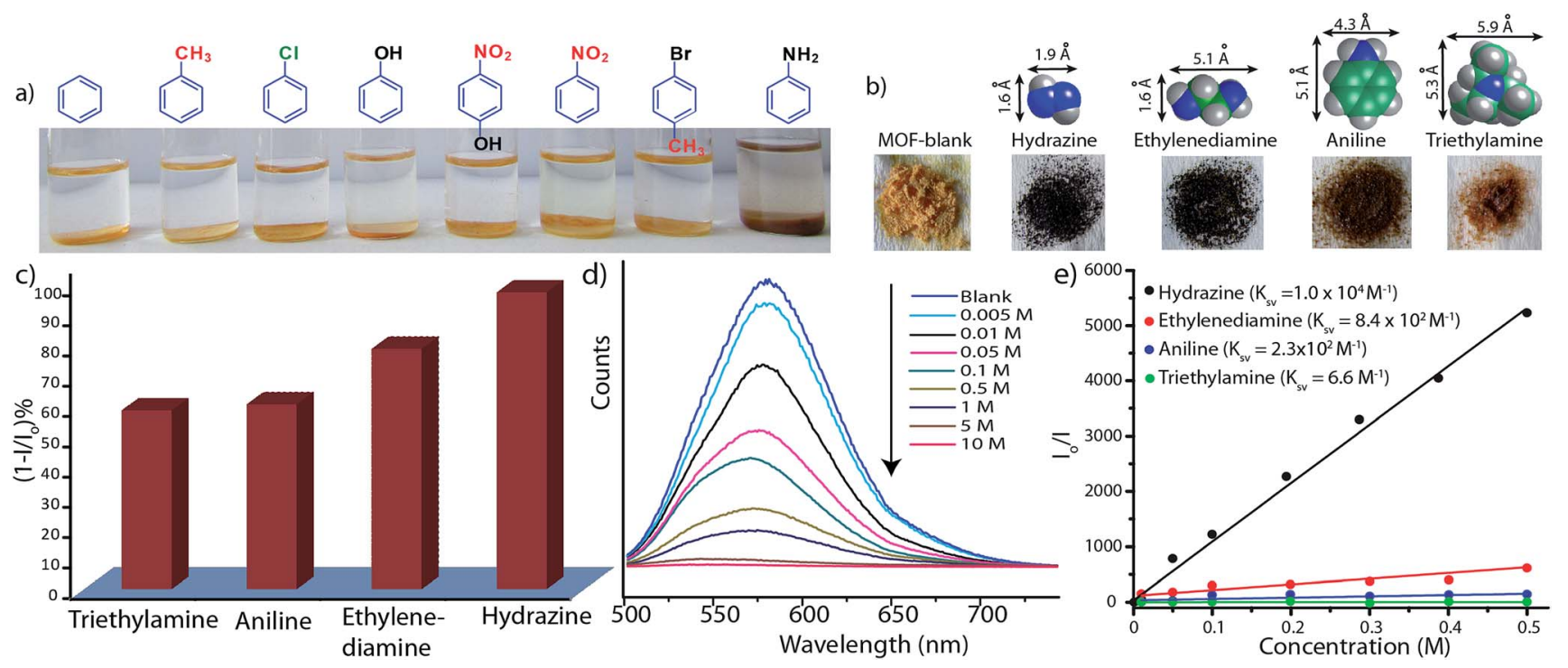

Fig. 4 (a) Photograph of selective detection of aniline over other aromatic functional molecules; (b) photograph showing the color change of $\mathrm{Mg}-\mathrm{NDI}$ samples in presence of different amines $(0.1 \mathrm{M})$; (c) bar chart representation for quenching efficiency of $\mathrm{Mg}-\mathrm{NDI}$ in presence of different amines $(0.01 \mathrm{M})$ in $\mathrm{EtOH}$; (d) reduction of PL emission intensities of $\mathrm{Mg}-\mathrm{NDI}$ by gradual increase in concentration of aniline; (e) Stern-Volmer plot for $\mathrm{Mg}-\mathrm{NDI}$ with different amines. 

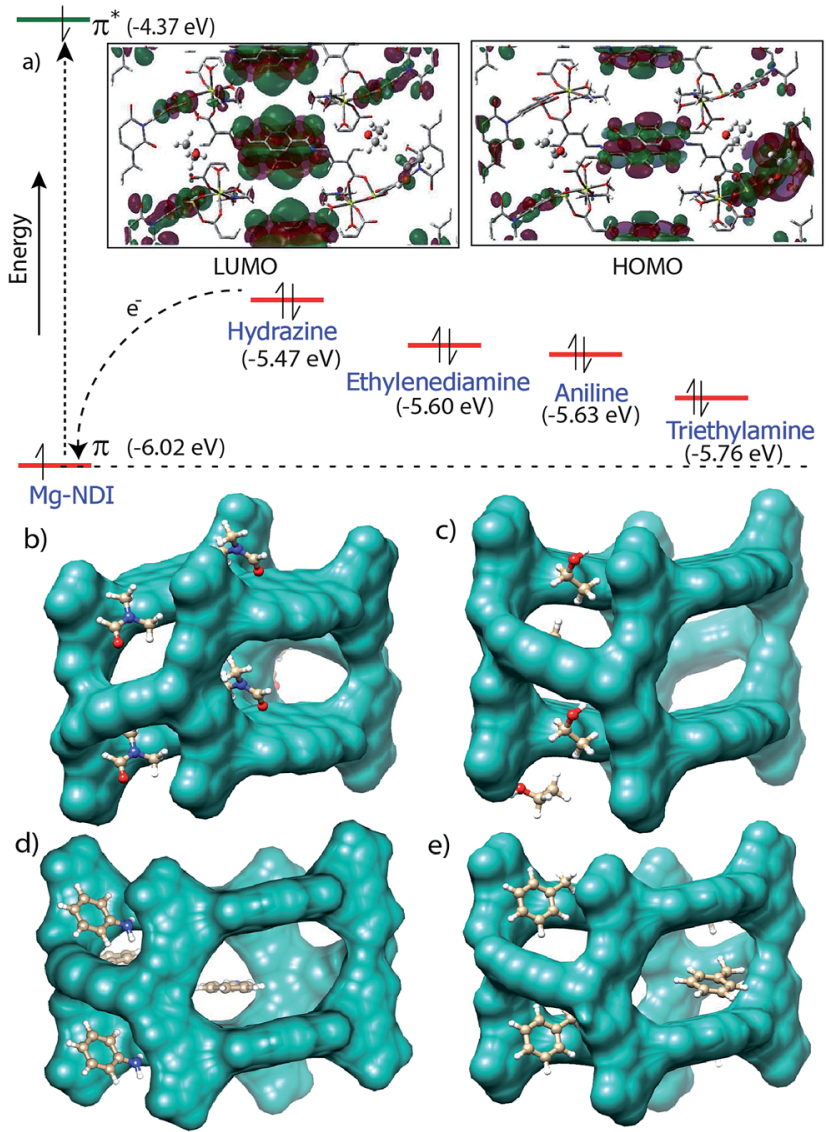

Fig. 5 (a) HOMO $(\pi)$ and LUMO $\left(\pi^{*}\right)$ energy levels of $\mathrm{Mg}-\mathrm{NDI}$ and different amines. The inset shows contour plots of the HOMO and LUMO for Mg-NDI. Energy optimized structures of (b) DMF, (c) EtOH, (d) aniline and (e) toluene incorporated $\mathrm{Mg}-\mathrm{NDI}$ has been represented.

Mg-NDI was exposed to the vapor of the amines (obtained from the evaporation of the pure liquid amines) for a period of $\sim 30$ min and then measured their photoluminescence property. It was observed that because of the exposure to the amine vapor, photoluminescence property of $\mathrm{Mg}-\mathrm{NDI}$ has been completely quenched, as that for amines from solution (Section S9 in ESI $\dagger$ ). Thus, Mg-NDI is also able to show vapor phase sensing for amines.

In order to get better understanding of the solvatochromic behavior and the corresponding PL quenching of Mg-NDI, DFT calculations were performed for bare and analyte incorporated MOFs, (Section S12 in ESI†). Optimized structures of the solvent incorporated MOFs (Fig. 5b and c) suggest that the solvent molecules have a weak dipolar interaction with the pore walls. Band gap energy for DMF@Mg-NDI and EtOH@Mg-NDI were found to be 1.32 and $1.41 \mathrm{eV}$, respectively. The calculated band gap values, calculated while keeping all framework atoms fixed in their crystallographic positions, are in accordance with the corresponding experimental band-gap values.

\section{Conclusion}

In conclusion, a new metal organic framework (Mg-NDI) has been synthesized using a NDI-based chromophoric linker.
Presence of the NDI moiety inside the framework made Mg-NDI capable of showing photochromic as well as solvatochromic property. Mg-NDI is able to demonstrate a quick (within 60 seconds) and reversible solvatochromic behavior in presence of solvents having different polarities. The photoluminescence emission maximum shows hypsochromic shift according to the increase in solvent polarity. Interestingly, the band gap of the solvent incorporated material was found to show a linear relationship with the solvent polarity. $\mathrm{Mg}-\mathrm{NDI}$ is also exhibit photochromism via electron transfer pathway because of the presence of the redox active organic linker. Mg-NDI also exhibits colorimetric and fluorescence sensor of small sized amine molecules. $\mathrm{Mg}$-NDI is able to selectively sense amine molecules, from a series of similar sized analytes, through prominent color change. Sensing of the mixed solvents detection is underway in our laboratory.

\section{Acknowledgements}

AM acknowledges CSIR for SRF and BG acknowledges UGC for JRF. RB acknowledges CSIR's XII ${ }^{\text {th }}$ Five Year Plan Project (CSC0122 and CSC0102) ) and CSIR-Young Scientist Grant (YSA000326) for funding. Financial assistance from DST (SB/SI/ IC-32/2013) is acknowledged. We acknowledge Dr S. K. Asha for providing photoluminescence spectroscopy facility. We also acknowledge Joyashish Debgupta and Dr V. K. Pillai for helping in electrochemical measurements.

\section{Notes and references}

1 (a) G. Lu and J. T. Hupp, J. Am. Chem. Soc., 2010, 132, 7832; (b) J. J. Gassensmith, H. Furukawa, R. A. Smaldone, R. S. Forgan, Y. Y. Botros, O. M. Yaghi and J. F. Stoddart, J. Am. Chem. Soc., 2011, 133, 15312; (c) M. D. Allendorf, R. J. T. Houk, L. Andruszkiewicz, A. A. Talin, J. Pikarsky, A. Choudhury, K. A. Gall and P. J. Hesketh, J. Am. Chem. Soc., 2008, 130, 14404; (d) L. E. Kreno, K. Leong, O. K. Farha, M. Allendorf, R. P. V. Duyne and J. T. Hupp, Chem. Rev., 2012, 112, 1105; (e) Z. Hu, B. J. Deibert and J. Li, Chem. Soc. Rev., 2014, 43, 5815; (f) Y. Cui, Y. Yue, G. Qian and B. Chen, Chem. Rev., 2012, 112, 1126.

2 (a) A. Hulanicki, S. Geab and F. Ingman, Pure Appl. Chem., 1991, 63, 1247; (b) J. R. Stetter, W. R. Penrose and S. Yao, J. Electrochem. Soc., 2003, 150, S11.

3 (a) M. E. Davis, Nature, 2002, 417, 813; (b) Z. Xie, L. Ma, K. E. deKrafft, A. Jin and W. Lin, J. Am. Chem. Soc., 2010, 132, 922; (c) J. Zhang, X. Liu, S. Wu, M. Xu, X. Guo and S. Wang, J. Mater. Chem., 2010, 20, 6453.

4 (a) H. Li, M. Eddaoudi, M. O'Keffee and O. M. Yaghi, Nature, 1999, 402, 276; (b) A. Mallik, S. Saha, P. Pachfule, S. Roy and R. Banerjee, J. Mater. Chem., 2010, 20, 9073; (c) H. Deng, S. Grunder, K. E. Cordova, C. Valente, H. Furukawa, M. Hmadeh, F. Gándara, A. C. Whalley, Z. Liu, S. Asahina, H. Kazumori, M. O'Keeffe, O. Terasaki, J. F. Stoddart and O. M. Yaghi, Science, 2012, 336, 1018; (d) F. Hinterholzinger, B. Rühle, S. Wuttke, K. Karaghiosoff and T. Bein, Sci. Rep., 2013, 3, 2562; (e) R. Grünker, V. Bon, 
P. Muller, U. Stoeck, S. Krause, U. Müeller, I. Senkovska and S. Kaskel, Chem. Commun., 2014, 50, 3450; (f) D. J. Xiao, E. D. Bloch, J. A. Mason, W. L. Queen, M. R. Hudson, N. Planas, J. Borycz, A. L. Dzubak, P. Verma, K. Lee, F. Bonino, V. Crocella, J. Yano, S. Bordiga, D. G. Truhlar, L. Gagliardi, C. M. Brown and J. R. Long, Nat. Chem., 2014, 6, 590; (g) W. M. Bloch, A. Burgun, C. J. Coghlan, R. Lee, M. L. Coote, C. J. Doonan and C. J. Sumby, Nat. Chem., 2014, 6, 906; (h) J. F. Van Humbeck, T. M. McDonald, X. Jing, B. M. Wiers, G. Zhu and J. R. Long, J. Am. Chem. Soc., 2014, 136, 2432; (i) P. Deria, W. Bury, J. T. Hupp and O. K. Farha, Chem. Commun., 2014, 50, 1965; (j) J. A. Mason, M. Veenstra and J. R. Long, Chem. Sci., 2014, 5, 32.

5 (a) B. Chen, L. Wang, F. Zapata, G. Qian and E. B. Lobkovsky, J. Am. Chem. Soc., 2008, 130, 6718; (b) Y. Li, S. Zhang and D. Song, Angew. Chem., Int. Ed., 2013, 52, 710; (c) B. Chen, L. Wang, Y. Xiao, F. R. Fronczek, M. Xue, Y. Cui and G. Qian, Angew. Chem., Int. Ed., 2009, 48, 500; (d) B. Zhao, X.-Y. Chen, P. Cheng, D.-Z. Liao, S.-P. Yan and Z.-H. Jiang, J. Am. Chem. Soc., 2004, 126, 15394; (e) J. Rocha, L. D. Carlos, F. A. A. Paz and D. Ananias, Chem. Soc. Rev., 2011, 40, 926.

6 (a) R.-B. Lin, F. Li, S.-Y. Liu, J.-P. Zhang and X.-M. Chen, Angew. Chem., Int. Ed., 2013, 52, 13429; (b) Z. Xie, L. Ma, K. E. deKrafft, A. Jin and W. Lin, J. Am. Chem. Soc., 2010, 132, 922; (c) Y. Takashima, V. M. Martínez, S. Furukawa, M. Kondo, S. Shimomura, H. Uehara, M. Nakahama, K. Sugimoto and S. Kitagawa, Nat. Commun., 2011, 2, 1; (d) M. M. Wanderley, C. Wang, C.-D. Wu and W. Lin, J. Am. Chem. Soc., 2012, 134, 9050; (e) A. Lan, K. Li, H. Wu, D. H. Olson, T. J. Emge, W. Ki, M. Hong and J. Li, Angew. Chem., Int. Ed., 2009, 48, 2334.
7 (a) Y.-Q. Lan, H.-L. Jiang, S.-L. Li and Q. Xu, Adv. Mater., 2011, 23, 5015; (b) J. An, C. M. Shade, D. A. Chengelis-Czegan, S. Petoud and N. L. Rosi, J. Am. Chem. Soc., 2011, 133, 1220; (c) H. Li, X. Feng, Y. Guo, D. Chen, R. Li, X. Ren, X. Jiang, Y. Dong and B. Wang, Sci. Rep., 2014, 4, 4366.

8 (a) B. Lee, R. Scopelliti and K. Severin, Chem. Commun., 2011, 47, 9639; (b) J. M. Landete, B. d. l. Rivas, A. Marcobal and R. Muñoz, Int. J. Food Microbiol., 2007, 117, 258.

9 (a) V. P. Aneja, P. A. Roelle, G. C. Murray, J. Schuthirland, J. W. Erisman, D. Faler, W. A. H. Asman and N. Patni, Atoms. Environ., 2001, 35, 1903; (b) X. Zhang, X. Liu, R. Lu, H. Zhang and P. Gong, J. Mater. Chem., 2012, 22, 1167; (c) Y. Che, X. Yang, S. Loser and L. Zang, Nano Lett., 2008, 8, 2219; (d) J. H. Bang, S. H. Lim, E. Park and K. S. Suslick, Langmuir, 2008, 24, 13168.

10 (a) Z.-Z. Lu, R. Zhang, Y.-Z. Li, Z.-J. Guo and H.-G. Zheng, J. Am. Chem. Soc., 2011, 133, 4172; (b) C.-Y. Sun, X.-L. Wang, C. Qin, J.-L. Jin, Z.-M. Su, P. Huang and K.-Z. Shao, Chem.Eur. J., 2013, 19, 3639; (c) R. Grünker, V. Bon, A. Heerwig, N. Klein, P. Müller, U. Stoeck, I. A. Baburin, U. Mueller, I. Senkovaska and S. Kaskel, Chem.-Eur. J., 2012, 18, 13299; (d) J. Cui, Y. Li, Z. Guo and H. Zheng, Chem. Commun., 2013, 49, 555.

11 L. Han, L. Qin, L. Xu, Y. Zhou, J. Sun and X. Zou, Chem. Commun., 2013, 49, 406.

12 (a) B.-P. Jiang, D.-S. Guo and Y. Liu, J. Org. Chem., 2010, 75, 7258; (b) L. Shi, C. He, D. Zhu, Q. He, Y. Li, Y. Chen, Y. Sun, Y. Fu, D. Wen, H. Cao and J. Cheng, J. Mater. Chem., 2012, 22, 11629; (c) X. Liu, X. Zhang, R. Lu, P. Xue, D. Xu and H. Zhou, J. Mater. Chem., 2011, 21, 8756. 